\title{
Design and manufacturing of the ITER ECRH Upper Launcher mirrors
}

\author{
Francisco Sanchez $^{1, *}$, R. Bertizzolo ${ }^{1}$, R. Chavan ${ }^{1}$, A. Collazos ${ }^{1}$, M. Henderson ${ }^{2}$, J.D. Landis ${ }^{1}$ \\ 1. Ecole Polytechnique Fédérale de Lausanne (EPFL), Centre de Recherches en Physique des Plasmas, Association EURATOM- \\ Confédération Suisse, CH-1015 Lausanne, Switzerland \\ 2. ITER Organization, Cadarache Centre, Saint Paul Lez Durance, France
}

\begin{abstract}
Four of the 16 ITER upper port plugs will be devoted to electron cyclotron resonance heating (ECRH) in order to control magnetohydrodynamic (MHD) instabilities [1]. In order to achieve the stabilisation of the neoclassical tearing modes (NTM) and sawtooth oscillation, a deposition of a very localized and peaked current density profile over a broad poloidal steering range is required. In the present optical configuration eight $2 \mathrm{MW}$ mm-wave beams enter each of the four upper launchers (UL) through waveguides into the vacuum vessel. Each beam line comprises consecutive corrugated waveguide sections with two mitre bends, orientating the poloidal and toroidal directions and three sections of quasi-optical transmission [3].
\end{abstract}

The beam waist locations and beam shaping properties in free space propagation are defined by two additional mirrors, the first being a static focusing mirror and the second a plane poloidally steerable mirror. Each mirror reflects a group of four mm-wave beams.

The three types of UL mirrors (mitre bend, focusing and steering) absorb heat generated essentially by three sources: the ohmic loss of the RF beam reflected at the mirror surfaces and the nuclear and thermal radiation coming from the plasma. While the average heat load is within reasonable engineering limits, three elements condition the actual mirror design, the peak ohmic heat load (Gaussian or Bessel type heat deposition profiles), the electromagnetic forces generated in vertical disruption events (VDE), and the ITER cooling water requirements.

This paper provides an overview of the different upper port-plug mirror designs and cooling schemes and an outlook on the prototype manufacturing activities and the future test program. The optimized mm-wave layout within the ECH port plugs is also presented.

Keywords: upper launcher, mirror, heat load, mirrors manufacturing

NOTE: The views expressed in this publication are the sole responsibility of the author and do not necessarily reflect the views of Fusion for Energy.

Neither Fusion for Energy nor any person acting on behalf of Fusion for Energy is responsible for the use which might be made of the information in this publication.

\section{INTRODUCTION}

A simplified view of the current front-steerable upper launcher design is shown in fig. 1. Eight circular $\mathrm{HE}_{11} 63.5 \mathrm{~mm}$ waveguides, (similar to the waveguide used in the transmission line) enter the port plug entrance on the right (note that there are four waveguides superimposed in this poloidal cut). Prior to the closure plate a diamond window and an in-line isolation valve is placed to provide the primary tritium barrier [3]. The waveguide continue after the closure plate to a free-space propagation from a set of mirrors (Lower Mirror 1,2 and Upper Mirror 1, 2 (from LM1 \&
LM2 to UM1 \& UM2) for a quasioptical configuration used to angle the 8 beams (both in toroidal and poloidal directions) to two focusing mirrors (UM3 \& LM3) with the incident

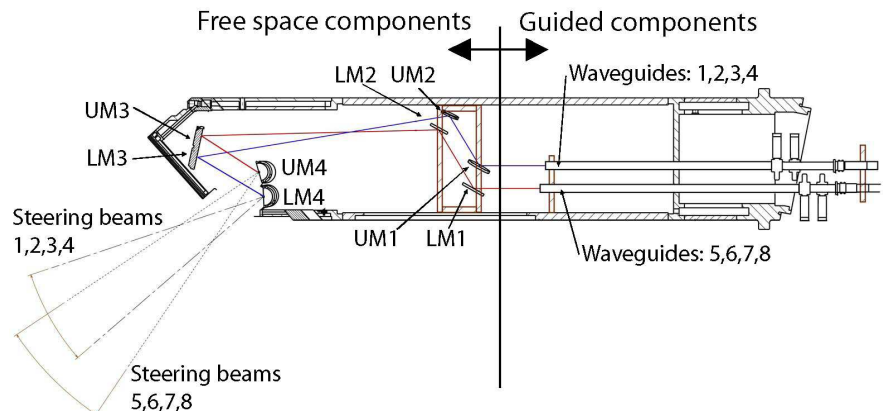

Figure 1. mm-wave transmission into the upper launcher 
beams partially overlapping in both toroidal and poloidal directions. The reflected beams are then directed downward to two flat steering mirrors (UM4 \& LM4), which redirect the beams into the plasma with a toroidal injection angle of $\beta \approx 20^{\circ}$. Four beams are incident on every single mirror, the overlapping of the beams permit the largest spot for a finite focusing mirror size within the confined space of the launcher, specially at the blanket shield module region.

The Quasi-optical design here outlined [2] has replaced the traditional waveguide \& mitre bends with free space mirrors, and increases flexibility in optics, reduces astigmatism, system complexity, component costs, volume occupied by beams and improves thermal efficiency by:

- Decreasing peak power densities: the highest cumulated peak power density on the mm-wave components occurs on the mitre bend mirrors. instead of this, the beams are expanded in free space such that the peak power density is reduced.

- Reduction of thermal loading in the waveguide: The mitre bends generate about $0.1 \%$ in higher order modes, half of which is absorbed in the neighboring waveguide sections requiring active cooling of the waveguide. Removing the mitre bends opens up the possibility to use radiative cooling techniques for the HE11waveguide, simplifying the design and maintenance.

The design of the steering mirrors (UM4 \& LM4) is critical in that it requires a light weight design for ease in rotating the mirror, and a good balance between thermal and electrical characteristics (minimizing stress, temperatures and the total induced current during a disruption event). A majority of the test procedures will be centered on this mirror, assuming that the other mirrors have less restrictive design parameters.

\section{HEAT LOAD ON THE MIRRORS}

The main contribution to the heat load on the mirrors is the ohmic loss of the reflected mm-wave beam . Every mirror is subject to four partially-overlapped $2 \mathrm{MW}$ incoming Gaussian beam, each beam with the following parameters:

$$
\frac{d P}{d A}=\frac{P_{0} \eta_{a b s} s}{\pi w_{m}{ }^{2}}\left[1+\cos ^{2}\left(\theta_{\text {inc }}\right)\right]
$$

Where $\mathbf{P}_{\mathbf{0}}$ : input power (2 MW),

$\mathbf{w}_{\mathbf{m}}$ : beam spot size on mirror

$\boldsymbol{\theta}_{\text {inc: }}$ beam incidence angle to mirror surface normal

s: surface roughness factor

$\boldsymbol{\eta}_{\text {abs: }}$ RF absorption factor (Fig. 2)

\section{A. Material dependency of ohmic mirror loss}

The ohmic loss depends on the surface resistance of the reflector, on the polarization and of the incident angle of the reflected wave. At the considered high frequencies the imaged current density (and the absorbed power) concentrates within a thin layer (skin depth) at the surface of the conductor.

Typically the skin depth is characterized by the mirror material, such as copper [8]. However, the plasma could erode the mirror surface, affecting to the absorption. In order to account this effect, the surface roughness factor s has been considered different for the plasma facing mirrors (UM4 \& LM4) $(s=2)$ and for the focusing and free space mirrors $(\mathrm{s}=1.3)$

TABLE I. shows the heat load to be removed per mirror for the current optical configuration.

TABLE I. HEAT LOADS ON FREE SPACE MIRRORS

\begin{tabular}{l} 
Steering mirrors (UM4 \& LM4) \\
Heat flux from plasma: $10 \mathrm{~kW} / \mathrm{m}^{2}=600 \mathrm{~W}$ \\
Volumetric (neutronic) heating: $1 \mathrm{MW} / \mathrm{m}^{3}=0.75 \mathrm{~kW}$ \\
Ohmic loss: (4 beams) $=26.8 \mathrm{~kW}$ \\
total heat to be removed $\sim 28.15 \mathrm{~kW}$ per mirror \\
Focusing mirrors ( UM3\& LM3) \\
Volumetric (neutronic) heating: $1 \mathrm{MW} / \mathrm{m}^{3}=7.35 \mathrm{~kW}$ \\
Ohmic loss: 4 x 2 MWx $0.2 \%=16 \mathrm{~kW}$ \\
total heat to be removed $\sim 23.35 \mathrm{~kW}$ per mirror \\
Volumetric (neutronic) heating: $0.1 \mathrm{MW} / \mathrm{m}^{3}=0.735 \mathrm{~kW}$ \\
Ohmic loss: $4 \mathrm{x} 2 \mathrm{MWx} 0.2 \%=16 \mathrm{~kW}$ \\
total heat to be removed $\sim 16.75 \mathrm{~kW}$ per mirror \\
Total heat to be removed is $\sim 170 \mathrm{~kW}$ (in-launcher free space mirrors) \\
Cooling water: inlet at $100 \pm 15 \mathrm{C}, 3.2 \mathrm{MPa}$ [7] \\
\hline
\end{tabular}

While the deposited averaged heat load is within reasonable limits, to remove the cumulated peak ohmic load in compliance with ITER structural design criteria and ITER cooling water requirements (reference) is the main challenge. A first approach could induce to a thick copper/ thin stainless steel mirror, but although it is a valid solution for most of the mirrors, in the case of a VDE the plasma facing steering mirrors are subjected to high electromagnetic forces, which set a limit for the size of the flexure pivots at the balanced configuration of the steering mechanism [4].

The thickness of the steering mirrors was designed to minimize the effective cross sectional area where the induced current can flow [5]. Ideally, the reflective surface should have high thermal and low electrical conductivity, but as copper is to be used as a reflective surface, it has to be relatively thin to minimize induced current during a VDE (fig. 2). The EM forces related to the induced currents during a disruption were estimated for the steering mirror in the worst configuration and assuming no shielding effect from the port wall, $\mathrm{dB}_{\mathrm{P}} / \mathrm{dt}=25 \mathrm{~T} / \mathrm{s}$ (plasma current $17.85 \mathrm{MA}$ and linear current decay time $0.04 \mathrm{~s}$ [11]) and $\mathrm{B}_{\mathrm{T}}=5.0 \mathrm{~T}$. The latest values given for disruptions of type II and III [12] were accounted and the resulting induced torque on the mirror is 
$<350 \mathrm{Nm}$, resulting in a force $<2100 \mathrm{kN}$ per flexure pivot on the current balanced configuration [5].

The second layer of the mirror is relatively thick $(\sim 15 \mathrm{~mm})$ and houses the cooling channels to evacuate the absorbed mm-wave power. The cooling channels will prevent current from being induced in the centre of the mirror. Although, current can flow above and bellow the cooling channels, the thickness has been reduced to a minimum specially at the edges.. The thermalmechanical stresses of this mirror are within ITER Structural Design Criteria requirements [6].

\section{THE FABRICATION ROUTE FOR THE STEERING MIRROR}

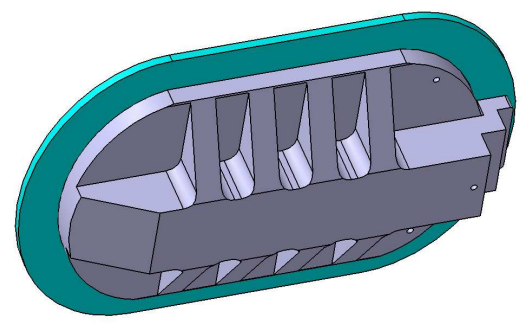

Figure 2. Front steering mirror

The following manufacturing methods were evaluated for joining the reflective copper surface, SS intermediate plate and SS cooling plate:

- Hot Isostatic Pressing (HIP)

- $\quad$ Brazing

- $\quad$ Electroplating

\section{A. Hot Isostatic Pressing (HIP)}

A mirror HIP prototype has been manufactured to insure that the powder HIP technique is a valid method in assembling the mirrors. There are two issues in particular that were being addressed, first the quality of joining of the SS316L to the copper and second maintaining the geometrical integrity of the cooling lines and mirror structure.

The joining of copper and SS powder has been shown to be enhanced by placing an inter-layer of nickel, and the quality of the join was good, with a high continuity and no voids appreciated. The control of the interface geometry and shape is the weak point of this method, which could drive to significant deformation of the cooling channel structure or the Cu-SS stepped interface.

\section{B. Electroplating}

Electroplating is an interesting option, but the size of the mirror plate (roughly, 290x $200 \mathrm{~mm}$ ) and the need of a thick $\mathrm{Cu}$ deposition at the center (4 mm thick) imposes a long time (> 250 hrs in a pyrophosphate bath). Due to the low current density in the center respect to the edges, first tests only reached 1.85 of 4 $\mathrm{mm}$ of deposition thickness at the mirror center after $100 \mathrm{~h}$ deposition. The current density profile makes the deposition rather in the edges than in the center, which is the opposite of the desired $\mathrm{Cu}$ profile. (fig.3).

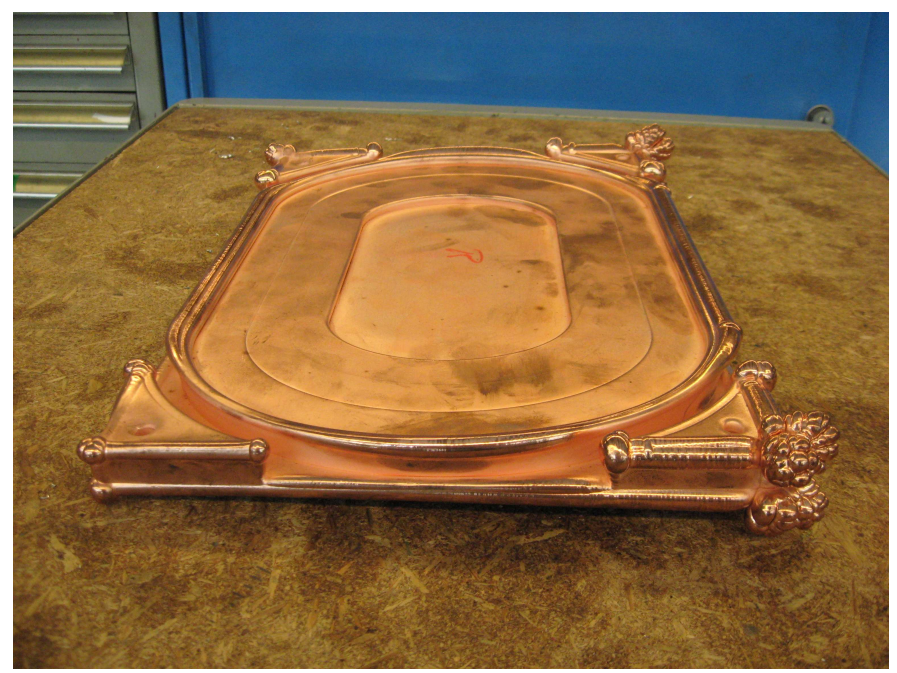

Figure 3. Mirror surface after electroplating

\section{Brazing}
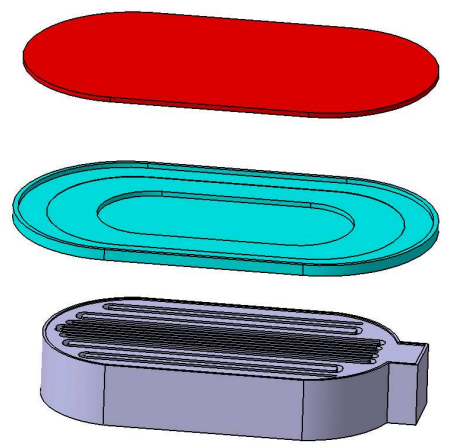

Figure 4. Mirror bodies for brazing

Brazing is a well-known technology, but the large areas require a careful control of the interface $\mathrm{Cu} / \mathrm{SS}$. In general, brazing defects have two effects:

- discontinuity in the exchange of the thermal stream between the absorber and the heat exchanger body

- $\quad$ the formation of pockets which are difficult to remove and which constitute eventual leaks or future hot spots/crack roots.

The main steps for the fabrication of the front steering mirrors within this schema are shown in fig and summarized as follows (fig. 4):

Step 1: Cutting the SS plates in the same laminar sense In order to guarantee a continuous brazing, the SS pieces to be brazed have to be cut in the same sense and follow an annealing heat treatment comprising high heating, followed by quick cooling in order to keep the homogeneous austenitic structure after return to ambient temperature.

Step 2: Starting from rough block: elliptical contour and elliptical pockets at bottom face (male of the previous piece): Important parameters of this operation are the required planity 
$(0,02 \mathrm{~mm})$ and the parallelism and perpendicularity $<0,01 \mathrm{~mm}$ Also to be taken into account, the last step of machining shall be done without heavy lubricating or with non-silicone based oils, as they are difficult to remove during the previous to brazing cleaning process. In our case, in order to obtain the required planarity (and avoiding an annealing treatment of the $\mathrm{Cu}$, which would make machining more difficult), an extra-thickness at the top-flat side was added. After a first (failed) attempt with $3 \mathrm{~mm}$ thick the required minimum extra-thickness for machining was determined to be $12 \mathrm{~mm}$ (fig. 5)

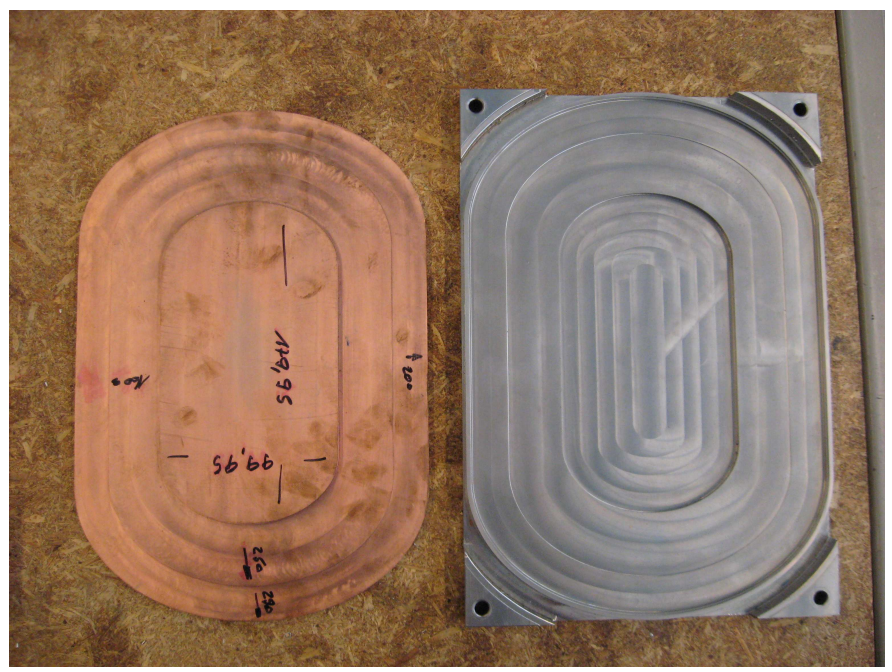

Figure 5. Mirror surface and intermediate plate before brazing

Step 3: Joining a machined Oxygen/halogen free copper to the machined intermediate plate by means of brazing.

The ultrasonic tests showed that a large area $(>50 \%$ of the total surface) was poorly brazed, which could produce thermal discontinuities and hot spots due to the peaked heat deposition. due to this the mirror was subject to solid HIP after brazing.

Step 4: Machining the interface groove on the intermediate piece and machining the cooling channels onto the bottom plate (fig. 6)

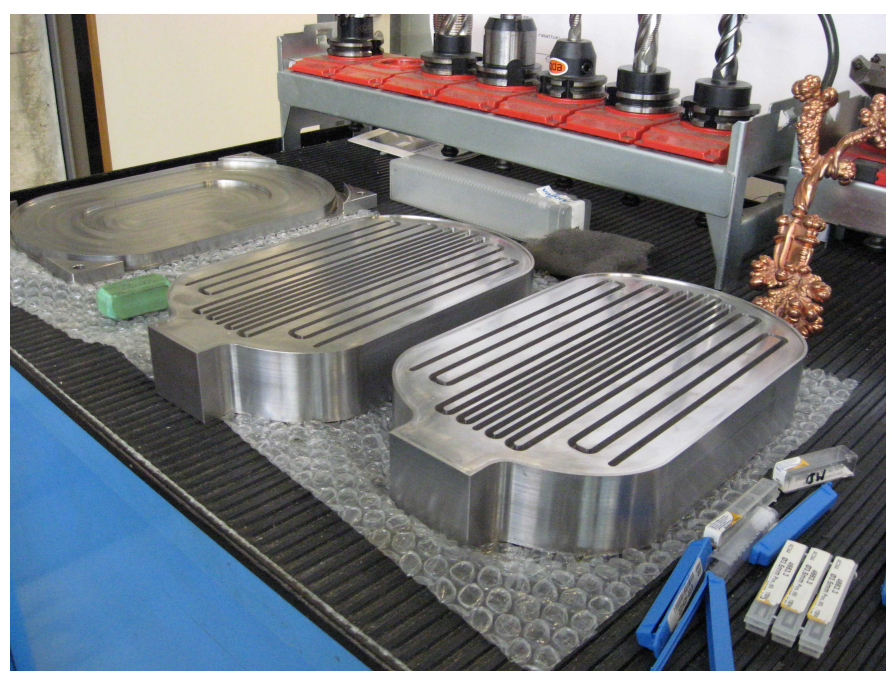

Figure 6. Cooling channels machined on bottom plate before brazing

\section{TEST PROGRAMME}

During the TW5 work programme, the mitre bend was identified as the component that experiences the highest peak power density $(\leq 4 \mathrm{MW} / \mathrm{m} 2)$ of all mm-wave components in the upper launcher [9]. Therefore, a high power RF test program was developed with the aim of demonstrating the feasibility of cooling such peak power densities in the ITER environment. The program was established in collaboration with JAEA and GA and integrated two mitre bends into the transmission line of the $170 \mathrm{GHz}, 1 \mathrm{MW}$ gyrotron test facility in Naka. The present optical (miterbend free) design will use of the experience gained through that testing program.

The test consisted on integrating a mitre bend into the transmission line of the $170 \mathrm{GHz}, 1 \mathrm{MW}$ gyrotron test facility in Naka. A second mitre bend was installed with the mirror coated with nickel to increase the surface resistivity by a factor of 1.9 to simulate even higher incident powers (up to $\sim 1.8 \mathrm{MW}$ ). Several diagnostic were used to diagnose the temperature rise of various components:

- Thermocouples embedded in mirror (provide cross check with ANSYS modeling)

- Absorbed power in mirror (estimates total absorbed power in mirror)

- Thermocouples on waveguide (estimates mode coupling increase due to mirror thermal deformations at higher incident powers)

- Absorbed power in waveguide cooling clamps (estimates mode coupling)

- Calorimetric load (monitors incident RF power)

An ANSYS model of the mirror was developed prior to the onset of the tests, which estimated the peak temperature rise, thermal profile on and in the mirror, thermal deformation of the mirror surface and thermal time constants of the cooling circuit. 
The actual experiments occurred in late February, 2007 with the participation of a CRPP representative. Incident powers of up to $0.7 \mathrm{MW}$ and pulse lengths between 400 and 1'000 s. were achieved.. Some results are shown in figure 3-6b, which are the measured absorbed power for both the copper and nickel mirror as a function of incident powers. The percentage of absorbed power was $0.22 \%$ for the copper and $0.42 \%$ for the nickel, which is approximately a $30 \%$ increase over the theoretical and low power absorption coefficients.

The test program for the free space mirrors (including the steering mirror ensemble) is summarized in TABLE II. It includes manufacturability, thermomechanical hydraulic and optical tests of each of the mirrors associated with the free space propagation of the beam through the launcher.

The mirrors will be either flat or focusing and all are assumed to have an optically polished copper surface. Note that the optical surface is not required for propagation but is important for optical alignment of the system using a laser.

The testing of the optical system at full power (four beams of $2.0 \mathrm{MW}$ ) and $\mathrm{CW}$ operation would require an expensive test facility with multiple gyrotrons. It is indeed more effective using an e-beam that can be swept across the mirror surface with the sweep speed varied to simulate the power density of the four incident beams on a given mirror. Or using the high resistive coating and a lower power source. Such a simulated test reduces the infrastructure costs and speeds up the testing process. Therefore the test program (listed in table Table II for the free space mirrors will be adapted to existing test facilities, to reduce $\mathrm{R} \& \mathrm{D}$ costs.

TABLE II. TEST PROGRAMME

\begin{tabular}{|c|l|}
\hline Thermal heat load & $\begin{array}{l}\text { Simulate 2MW with artificially } \\
\text { increased absorption (using TiO2 or ni } \\
\text { coating on the mirror surface) and multi } \\
\text { beam footprint (from a deformed single } \\
\text { beam) (in collaboration with JAEA) }\end{array}$ \\
\hline Pressure testing & $\begin{array}{l}\text { Proof pressure testing of the } \\
\text { coolant circuits according to ITER } \\
\text { requirements (6.25 MPa, equivalent to } \\
1.25 \text { times the design pressure [6]. }\end{array}$ \\
\hline Surface reflectivity & $\begin{array}{l}\text { Measurement of the surface } \\
\text { reflectivity of various mirror materials } \\
\text { to determining the expected thermal } \\
\text { loading of the mirrors (performed by } \\
\text { CNR and IPF) }\end{array}$ \\
\hline Surface roughness & $\begin{array}{l}\text { Determine a realistic surface } \\
\text { roughness factor s, for estimating the } \\
\text { increased absorption beyond that of } \\
\text { nominal ohmic losses (performed by } \\
\text { CNR and IPF) }\end{array}$ \\
\hline
\end{tabular}

\section{CONCLUSIONS}

The thermal loads of the ITER ECH upper launcher mirrors are within reasonable limits, and they are lower than the ones expected for already tested mitrebend mirrors. The design of the steering mirrors (UM4 \& LM4) is critical in that is subject to both high peaked thermal loads and electromagnetic forces during VDE events, requiring a light weight design for ease in rotating the mirror, and a good balance between thermal and electrical characteristics (minimizing stress, temperatures and the total induced current during a disruption event). thickness of the steering mirrors was designed to minimize the effective cross sectional area where the induced current can flow. The key of success in manufacturing of the front steering mirror, is a good joint between the multi-thickness layer of $\mathrm{Cu}$ (which variates from $0.3 \mathrm{~mm}$ at the edges to $4 \mathrm{~mm}$ at the center) and the SS cooling plate. While none single method is totally adapted to that kind of geometry, a method that joins brazing with a post-brazing solid HIP looks promising (at the moment of writing this paper, the ultrasonic test for the joint quality are underway). As a brief resume of the difficulties encountered, HIP is the most difficult manufacturing method because the difficulty of controlling the geometry, brazing has the risk of larger voids and internal discontinuities, and electroplating such a $\mathrm{Cu}$ thickness $(4 \mathrm{~mm})$ in the center of a large area $(200 \times 300 \mathrm{~mm})$ is a very demanding task. High power testing is envisioned in 2009.

\section{ACKNOWLEDGMENTS}

This work, supported by the European Communities under the contract of Association between EURATOM-ConfederationSuisse, was carried out within the framework of the European Fusion Development Agreement (EFDA) and Fusion for Energy (F4E). The views and opinions expressed herein do not necessarily reflect those of the European Commission.

\section{REFERENCES}

[1] H. Zohm, "The ITER ECRH upper launcher - physics goals and design requirements", Proc. 13th ECE \& ECH, Nizhny Novograd (2004), http://www.ec13.iapras.ru/on-line-papers.htm

[2] M.A. Henderson et al,Overview of the ITER EC upper launcher, Nuclear fusion 48 (2008) 050413

[3] R. Chavan et al. The ECH front steering launcher for the ITER upper port, Fusion Engineering and Design 82 (5-14) (2007) 867-872

[4] J.D Landis et al. Design of the critical components in the ITER ECH upper launcher steering mechanism, Fusion Engineering and Design 82 (5-14) (2007) 897-904

[5] F. Sanchez et al, Design status of the ITER ECH upper launcher mirrors, Proc., 22 Simposium on Fusion Engineering, Albuquerque (2007)

[6] Structural Design Criteria for ITER in-vessel components (SDC-IC), G74 MA 8 R0.1, July 2004

[7] J. How, ITER Project Integration Document, ITER Design integration Division, release 3.0, January 2007.

[8] R. Chavan et al. Design and testing of the ITER ECRH Upper Launcherthermo-mechanical analysis of the design changes. 19-22 EFDA TW3-TPHEECHULB3/03-1062/a31

[9] M.A.Henderson et al. Progress in the ITER upper launcher mm-wave system, component design and testing. proc 15 Joint workshop on Electron-Cyclotron Emission and Resonance (EC-15, california 2008 